\title{
Benefícios Potenciais de Plantas Daninhas: I. Nutricêuticos e Fitodescontaminantes Ambientais ${ }^{1}$
}

\author{
Potential Benefits of Weeds: I. "Nutraceuticals" and Phytoremediation \\ CHRISTOFFOLETI, P.J. ${ }^{2}$
}

\begin{abstract}
RESUMO - As plantas daninhas interferem nas atitudes humanas tanto em ambientes agrícolas como em não-agrícolas, em razão da adaptabilidade aos nichos deixados pelas culturas. Dessa forma, a maioria das pesquisas desenvolvidas com plantas daninhas objetiva o manejo racional e sustentável nos agroecossistemas. No entanto, muitas das plantas geralmente consideradas daninhas apresentam benefícios. É necessária a devida atenção às pesquisas, visando a descoberta das propriedades nutricêuticas e fitodescontaminantes ambientais, embora existam diversas outras virtudes nessas plantas não consideradas nesta abordagem. Não é objetivo do artigo prestar esclarecimento sobre a utilização e as propriedades dos compostos largamente consumidos pela população nas últimas décadas, mas sim alertar pesquisadores para que desenvolvam trabalhos nessa área, pois o potencial de utilização das plantas daninhas é muito grande. É necessária a integração de pesquisadores não só da ciência das plantas daninhas, mas também de outras ciências relacionadas, visando soluções para problemas como produção de alimentos e preservação da natureza.
\end{abstract}

Palavras-chave: agroecossistemas, manejo racional, manejo sustentável.

\begin{abstract}
Weeds adversely affect humans in agricultural and nonagricultural environments because their ability to occupy niches left by agricultural crops. Therefore, most of research in Weed Sciences aims a rational and sustainable management of agricultural ecosystems. However, a great number of plant species, generally classified as weeds, have potential benefits. Thus, this article focus on the need of further research on "nutraceuticals" and environmental phytoremediation weed properties, even though there are several other weed beneficial properties not considered here. It is not the objective of this article to elucidate the use, and properties of such compounds which are extensively consumed by humans, but to call researchers, attention to the fact that there is a great potential for weeds to be used for this purpose. Thus, a multidisciplinary integration approach to food production solutions and nature preservation is needed.
\end{abstract}

Key words: agricultural ecosystems, rational management, sustainable management.

\section{INTRODUÇÃO}

As plantas daninhas são definidas como vegetais indesejáveis às atividades humanas num determinado momento e local; assim, essas plantas terão sempre caráter antropomórfico. Sempre que o ambiente é manipulado pelo homem na prática da agricultura, surgem nichos que são adequados a certas espécies de plantas daninhas. Estas plantas, também denominadas daninhas, interferem nas produções agrícola, florestal e animal e até na saúde humana de forma significativa. O impacto econômico causado pelas plantas daninhas na

\footnotetext{
1 Recebido para publicação em 11/1/2001 e na forma revisada em 13/3/2001.

2 Professor Associado - Departamento de Produção Vegetal da Escola Superior de Agricultura “Luiz de Queiroz" - Universidade de São Paulo, Av. Pádua dias, 11, Caixa Postal 09, 13418-900 Piracicaba-SP, <pjchrist@ carpa.ciagri.usp.br>.
} 
agricultura implica a adoção de medidas de manejo, visando minimizar os efeitos negativos destas plantas na agricultura e em outras atividades humanas. No entanto, a biodiversidade das espécies de plantas unilateralmente classificadas como daninhas é muito grande, criando possibilidade de utilização destas plantas de forma benéfica, destacando-se como nutricêuticos e fitodescontaminantes ambientais, embora diversas outras aplicações úteis possam ser facilmente enumeradas. Aliás, uma das definições também encontradas na literatura sobre planta daninha refere-se a plantas cujas virtudes ainda não foram descobertas.

\section{Nutricêuticos}

Os nutricêuticos são produtos cuja finalidade é suplementar a dieta, de modo concentrado, de um agente que se presume ser bioativo, normalmente encontrado em alimentos, porém em baixas concentrações. Eles são prescritos na forma não-convencional de alimentação (pílulas, comprimidos, rações, etc.) e utilizados com a intenção de tornar o organismo comensal mais saudável, pois as doses administradas são maiores que as obtidas de alimentos normais. Diversas outras terminologias são utilizadas para designar os nutricêuticos, como fitoquímicos, suplementos alimentares, alimento medicinal, alimentos funcionais (alimento com função fisiológica), termos estes que foram literalmente traduzidos da língua inglesa, sendo todos considerados sinônimos de nutricêuticos; fica, pois, a critério do leitor a designação desses produtos, uma vez que, provavelmente, não existe terminologia consensual.

Deixando de lado os aspectos nutritivos e medicinais destes produtos, que, a propósito, não é especialidade do autor, o interesse do público em geral pelos nutricêuticos tem aumentado grandemente nos últimos 10-15 anos, apesar de os benefícios serem conhecidos na cultura chinesa desde 100 a.C. (Chen \& Weng, 1998). O mercado estimado dos nutricêuticos nos Estados Unidos foi de 14 bilhões de dólares, durante o ano de 2000 (Zeisel, 1999). Presumese que no Brasil este mercado seja também bastante expressivo, tendo em vista a evidente preocupação da população com a manutenção da forma física saudável.
As pessoas familiarizadas com a terminologia científica da classificação botânica das espécies vegetais, por serem conhecedoras dos nomes comuns de plantas, certamente devem ter notado, nos frascos desses produtos, que alguns deles são preparados a partir de plantas consideradas daninhas. Existe grande potencial de uso das plantas daninhas e das plantas não-cultivadas como fonte de nutricêuticos. A planta daninha Fagopyrum esculentum e a erva-de-são-joão "St. Johnswort" (Hypericum perforatum) são consideradas suplementos alimentares. No Brasil praticamente não há pesquisas nessa área, mas, em razão da biodiversidade das nossas plantas daninhas, com certeza existe grande potencial a ser explorado. Hall et al. (2000) sugerem aos pesquisadores da ciência das plantas daninhas que trabalhos sejam desenvolvidos com dois enfoques principais: a) screening de espécies de plantas daninhas que tenham relação taxonômica próxima com culturas hortícolas como tomate, crucíferas e alho; e b) determinação do potencial de certas espécies daninhas, visando produção, processamento e comercialização de nutricêuticos.

\section{Fitodescontaminantes Ambientais}

Algumas plantas consideradas daninhas também podem ser usadas como descontaminantes dos metais pesados do solo e da água. Em grandes volumes de água, os metais pesados são difíceis de ser retirados, exigindo tratamento terciário, fato este improvável na estação de tratamento de água. Atualmente a técnica mais utilizada na descontaminação de solo com metais pesados é a imobilização ou extração por meio de métodos físico-químicos. Estas técnicas são caras, visto que exigem equipamentos sofisticados e destroem as atividades biológicas e físicas dos solos agrícolas (McGrath et al., 1994). As plantas daninhas, no entanto, têm grande potencial como extratoras destes metais, podendo ser usadas para retê-los, via sistema radicular, evitando a lixiviação ou movimentação até outras áreas. Este processo é conhecido como fitodescontaminação, terminologia esta ainda não-usual cientificamente, mas que parece adequada.

Há dois tipos de fitodescontaminação: fitoestabilização e fitoextração. O primeiro envolve a estabilização do contaminante do solo, 
diminuindo assim a sua movimentação no ambiente. A fitoextração envolve a remoção do metal pesado do solo ou da água e o acúmulo na parte aérea. Pouca experimentação foi desenvolvida até o momento com as plantas daninhas que têm potencial de uso como descontaminante de solo e água. No Brasil, estes trabalhos são praticamente inexistentes. Assim, Hall et al. (2000) sugerem que sejam conduzidas pesquisas em: a) prospecção de espécies com capacidade de acumular e tolerar altas concentrações de metal pesado; b) avaliação de características biológicas das plantas que favoreçam a tolerância e o acúmulo de metais pesados; c) programas de melhoramento das plantas daninhas, objetivando características biológicas envolvidas com a maior quantidade de metais pesados, por meio de procedimentos tradicionais ou técnicas moleculares; e d) análise do custo/benefício da técnica de fitodescontaminação ambiental.

\section{CONSIDERAÇÕES FINAIS}

Foi objetivo deste estudo conscientizar os pesquisadores e o público em geral de que as plantas daninhas, ou simplesmente mato, apresentam grande biodiversidade e, portanto, têm grande potencial de utilização benéfica, não apresentando apenas características danosas à agricultura ou a outras atividades humanas. Não se pretendeu com o artigo salientar a importância dos nutricêuticos ou fitodescontaminantes ambientais, uma vez que este assunto é dos especialistas da área, mas contribuir para que pesquisadores da ciência das plantas daninhas observem doravante os aspectos benéficos das plantas consideradas daninhas e, assim, trabalhem em conjunto com outras áreas das ciências, objetivando o bemestar da humanidade, por meio de recursos da própria natureza.

\section{LITERATURA CITADA}

CHEN, J.; WENG, W. Medical food: the Chinese perspectives. J. Med. Food, v.1, p.117-122, 1998.

ZEISEL, S.H. Regulation of "nutraceuticals". Science, v.285, p.183-1855, 1999.

HALL, J.C.; van EER, L.L.; MILLER, S.D.; OWEN, M.D.K., PRATHER, T.S., SHANER, D.L., SINGH, M., VAUGHN, K.C., WELLER, S.C. Future research directions for weed science. Weed Techn., v.14, n.3, p.647-658, 2000.

McGRATH, S.P.; SIDOLI, C.M.; BAKER, A.J.M; REEVES, R.D. Using plants to clean up heavy metal in soil. In: WORLD CONGRESS OF SOIL SCIENCE, 15, 1994, Acapulco, México. Proceedings... Madison: WI: International Soil Science Society, 1994. p.310-312. 